\title{
A Review of the Controversy between Virtue Ethics and Normative Ethics
}

\author{
Xi Fang \\ School of Philosophy and politics Law \\ Yunnan Normal University \\ Kunming 650500, China; \\ fangxi1982@126.com
}

\author{
Juanjuan Wang \\ School of philosophy \\ Hubei University, \\ Wuhan, Hubei, 430062, China; \\ 583528588@qq.com
}

\begin{abstract}
The purpose of this study is to make a comprehensive and systematic review of the related literature of the debate between western contemporary ethics and normative ethics, and to show its development in a clearer way so that everyone can benefit from it. Although great progress has been made in the study of this academic debate in the domestic and foreign academics, there is still a lack of deep research and systemic problems. This article is to combine the research status of the debate between virtue ethics and normative ethics. In addition, the lack of research on this academic controversy is analyzed and reviewed objectively, and the research content of this academic controversy is prospected, and some important research conclusions and revelations are drawn up, which will help to accumulate very thick academic support and academic resources for the relevant research at home and abroad.
\end{abstract}

Keywords - virtue ethics; normative ethics; debate research

\section{INTRODUCTION}

Since the 1950s, with the deepening of the study of moral ethics, the western ethical circles have launched a fierce and lasting debate on the attribution and differences between virtue ethics and modern normative ethics, which are represented by utilitarian and obligatory ethics. This debate has brought forth many ethical issues that are changing in the times, and almost constitute the whole content of Western Ethics Development in recent 30 years. On the one hand, it not only promotes the development of contemporary western ethics theories towards integration and perfection, but also has extremely important academic significance. On the other hand, it is of great practical significance to reflect the crisis and plaguing the contemporary human beings, and to provide different options for overcoming the problems faced by modern civilization. [1]The systematic discussion of the controversy between the two kinds of ethics will not only help us to grasp the frontier, development trend and future trend of Western Ethics in the past 30 years, but also expand and deepen the research of contemporary Chinese ethical theory, and strengthen the deep concern of Chinese ethical theory to the practical problems.

\section{RESEARCH SITUATION AT HOME AND ABROAD}

\section{A. A survey of domestic research}

From the perspective of domestic academia, this academic debate can be roughly divided into two stages. In the first stage, the stage of translation: this part mainly focuses on Macintyre and Aristotle, such as professor Song Jijie's translation of After
Virtue (2003), Professor Xu Xiangdong's Ethics and Moral Requirements of Virtue (2007), The Fragility of Good: The Luck and Ethics of Ancient Greek Tragedies and Philosophies (2007), moral luck (2007), Consequence doctrine and obligation (2011), and Professor Liao Shenbai's translation of Nicomachean Ethics, (2004), and so on. The second stage, the summary stage: the early researchers (experts) such as Jun Wan, Jiang Chang, Xu Xiangdong, Gong Qun, Gao Guoxi, Chen Zhen, as well as young scholars, Ge Siyou, Li Yitian, Fang Dezhi, Zhao Yonggang. On the one hand, these two parts of experts and scholars have provided us with a comprehensive description of the basic concepts, basic positions, research methods, theoretical types and some criticism of contemporary western ethics of virtue, utilitarianism and the ethics of obligation. [2]Among them, Professor Jiang Chang's Virtue Theory (2011) and The history of Western Virtue (2016) are the most comprehensive and in-depth researches on virtue. On the other hand, it reflects the future trend of contemporary domestic scholars in this academic debate, which advocates complementarity and cooperation between the two camps, rather than differentiation and opposition, [3]in particular, Dr. Li Yitian's Virtue Ethics and Moral Diversity (2012) and Dr. Zhao Yonggang's Virtue Ethics: the independence of a moral type (2011).

\section{B. A survey of foreign research}

From the foreign academic circles, Generally speaking, based on the identity of people's social community, virtue ethics discusses the adaptation of human's psychological quality to the identity of their community. Normative ethics is based on the theory of human atomism, which discusses the adaptation of human behavior to modern contract society. [4]The controversy between the two camps of contemporary western moral ethics and normative ethics stems from the rapid development of Contemporary Western Psychology (especially female/ gender psychology) and the deep reflection on the traditional rationalist rule ethics represented by utilitarianism and the theory of obligation. The debates between these two can be roughly divided into the following three stages.

1) The first stage, the criticism of virtue ethics to normative ethics (utilitarianism and deontology) includes: first, the criticism of normative ethics ignore person's Moral Psychology (virtue), and just talk about moral principles, such as Anscombe (G.E.M.Anscombe) reveals that the core of modern ethics is rule based. And ethical research must be based on 
human moral psychology. Second, the criticism of normative ethics, which will be self-contradictory in the argumentation of "moral principles", and it is a never-ending arena. If Macintyre (Macintyre) in pursuit of virtue, he believes that the moral argumentation of Modern Enlightenment thinkers will eventually fall into a negative situation. Third, Criticizing and denying the problem of "moral luck". Rule ethics emphasizes that person's subjective will is the principle of "One size fits all" to evaluate human behavior, to deny the influence of contingency on moral behavior, and to consider moral problems as an objective necessity. In reality, the problems of "absurdity" or "paradox" appeared in the reality, such as Williams (Bernard Williams), for example, that the moral behavior of man is subject to luck, which is related to "moral luck". Fourth, to criticize normative ethics and ignore human's emotional problem. As Michael Slote believes, Normative ethics and new Aristotle's moral ethics all emphasize the "consistency" of rationality in human virtue, but ignore the inconsistency of emotion itself (such as the skewness characteristic of "care" virtue), and so on.

2) The second stage, normative ethics (utilitarianism and deontology) is an anti-criticism of virtue ethics. first, refutation of moral ethics is self-centered. For example, Tim Scanlon, is opposed to the sense of virtue ethics, which is a moral of welfare, and thinks that happiness looks more like self - interest. Second, refuting virtue ethics cannot provide correct action guidance and cannot be universal, such as Robert B.louden (Robert) believed that virtue is not the sufficient condition for correct action, and the person of virtue may make wrong action. Third, refutation of virtue ethics is difficult to apply to practice, such as Daniel Statman (Daniel Statman), which points out that moral ethics cannot provide the corresponding standard to make a choice between the moral dilemma, and can not be used as a universal norm suitable for the acceptable behavior as the basis of the legislation. Forth, refutation of virtue ethics is faced with the problem of cultural and moral relativism, which can only be used as a "supporting angle" of normative ethics, such as Robert B.louden (Robert), which shows that virtue is only a derivative of utilitarianism or a concept of obligation, without independence, and so on.

3) The third stage, the integration of virtue ethics and normative ethics (utilitarianism and deontology) will reinterpret western traditional moral issues in the new era. [5] First, in the normative demonstration of moral ethics, according to Rosalind Hursthouse's work--on moral ethics, demonstrates that moral ethics is also of a regular nature, based on 'the actor", the way of virtue evaluation of Aristotle. Therefore, virtue ethics, utilitarianism and obligatory ethics are the three modern normative ethics. Second, the ethical interpretation of normative ethics, such as in "the moral of motivation" and "moral emotionally", Michael Slote believes that many problems of modern normative ethics centered on reason and individual rights (self-discipline, rights, equality, justice, etc.) can be returned to the epistemology of emotionally (virtue) and reinterpreted. Third, Furthermore, after Socrates proposed the "virtue is knowledge" (that is, the question of virtualization/ conceptualization of virtue), the contemporary ethics of virtue begins to reflect on the (emotional) or moral problems in scientific knowledge, namely, the virtualization/situational question of knowledge, and so on, and the integration of this new method is promoted. And the rapid development of Cognitive Science (Psychology) and applied ethics in recent ten years in the West has been achieved. [6]

\section{Research EVAluation AND PROSPeCt}

\section{A. Research and analysis}

To sum up, although great progress has been made in the study of this academic debate in the domestic and foreign academics, there are still not enough deep research and systematic problems, which are embodied in the following shortcomings. On the one hand, foreign scholars often argue about a certain content based on personal academic views. Although their theoretical conclusions are unique, there is a widespread problem of strong personal color and a lack of historical and cultural horizons. Contemporary unilateralists and obligators are particularly obvious in this respect. At the same time, a review of the gains and losses of the arguments between the two schools of debate. On the whole is weak, the lack of comprehensive and thorough combing and research, it is difficult to make the readers and to distinguish between right and wrong. On the other hand, the domestic scholars do not pay enough attention to the relevant treatises on the debate between the two schools from their social and historical conditions, cultural traditions and social movements, and thus fail to reveal the social essence and internal logic of the disputes between the two schools. At the same time, there is no convincing comment on the influence and function of the two schools of debate. Most scholars have multiple introductions. It is difficult to grasp the theoretical and contemporary values of the controversy between the two schools. [7]Therefore, how to look at and comment on the academic value and practical significance of the controversy between the two schools and how to make a more systematic and profound analysis and evaluation of the controversy between the two schools is still an important dimension to deepen our research. Our research on the theme of the debate between virtue ethics and normative ethics is summarized into five parts.

\section{B. Research prospect}

1) The first part is that the era background and ideological condition of debates between virtue ethics and normative ethics. The purpose of this part is to analyze the historical inevitability and rationality of the controversy between the two schools. From the historical inevitability, the defects of modern civilization and its social problems caused many western thinkers to think hard, reflect on the current mainstream values and mainstream ideology and begin to criticize modern ethics, thus the controversy of the two schools came into being. From the point of view of rationality, ethics is the philosophy of life. What kind of life is to be studied and answered is the problem of good life and how to live a good life. Ethics should not only study the value and happiness of life, but also study the problems of kindness, virtue and norm, and study the relationship between them. [8]In this sense, with the revival of virtue ethics, this academic debate is beyond reproach.

2) The second part is that virtue ethics criticizes and defends normative ethics. This section aims to elaborate on the criticism and defense of this academic debate. In the critical 
aspect, the subject will focus on the "rebellion" of the contemporary western moral ethics, mainly aiming at the general concepts of moral rules, moral obligations and other basic concepts, as well as moral requirements, moral luck, thinking of life and other issues, and in order to define the two theories themselves. In the defense aspect, utilitarianism and ethnics ethics defended their claims against the objections of German ethicists. We strive to further clarify the interpretation of virtue based on clarifying our position through this criticism and defense process. This is actually the first stage of the revival of virtue ethics.

3) The third part is that normative ethics is an anticriticism and defense for virtue ethics. The purpose of this part is to elaborate the anti-criticism and defense of this academic debate, which is intended to deepen the key research content of this subject and to show the full picture of this academic controversy. In the aspect of anti-criticism, the subject will focus on the key issues, such as self-centered, behavior guidance, difficult application, moral luck and the independence of virtue concept. On the contrary, the ethics of virtue ethics also defended one by one for the criticism of utilitarianism and the ethics of the ethics of obligation, and also made some amendments to his own theory. We strive to reveal the unprecedented rapid development of western ethical theory through the process of this anti criticism and defense, and the ethics of virtue has also entered the stage of theoretical construction.

4) The fourth part is that the advantages and disadvantages of each theory of virtue ethics and normative ethics. The purpose of this part is to elaborate on the contents, methods and values of the two schools' debates. We will compare and demonstrate the main contents of the two schools' disputes in their specific era environment, cultural tradition and social movement background. It is not influenced by the level of cognition and the extreme attitude. To clarify the context and track of the controversy between the two schools. Seeking truth from facts and commentary on the gains and losses of the theories of the parties, a clear argument is not a matter of winning or losing. Their respective contributions, advantages and disadvantages, and difficulties are studied. For example, we try to solve the problems of how moral ethics and utilitarianism and ethics itself have the common problems of how to prove our ethical beliefs to be correct or to provide the basis for them, as well as the many differences that exist between moral ethics.

5) The fifth part is that the academic value and practical significance of debates between virtue ethics and normative ethics. The purpose of this part is to further promote the depth and depth of research from the perspective of contemporary China and the development of human society. From the academic value, through the two schools of debate to give a comprehensive combing and macro analysis, the frontiers and the times of the dispute between the two schools outline the general landscape and general trend of the frontier development of contemporary ethics, and promote the relevant research in China into the academic frontier of the world and explore the future development and future of the whole human being. From the practical point of view, it illustrates the beneficial enlightenment of the controversy between the two schools of debate on the problems facing the development of contemporary mankind and China, such as the ecological environment, the reproductive ethics, the human cloning, and many traditional or new fields which have not met the ethical problems of a large number of predecessors. "With Chinese characteristics" or the brand of "made in China" has not been solved such question about "a great lack of belief ethics" very well. And it is becoming a part of the contemporary Chinese society, especially in terms of moral ethics--“outstanding social equity and justice”.

\section{CONCLUSIONS}

In conclusion, the study of the debate between virtue ethics and normative ethics has unique academic value and application value. From the perspective of academic value, we can promote the further development of contemporary western ethics theory research, expand and deepen the research of Chinese ethical theory. This is the first effort to make a systematic and thorough study of the two schools of debate, and the mutual criticism and refutation prompted them to reflect and clean up their own theories. On the one hand, virtue ethicists established many become an independent school theory opens up a field for the theory of virtue ethics. On the other hand, the utilitarian and the obligators promoted their new development by absorbing the strengths of virtue interpretation, thus the whole western ethical theory has achieved unprecedented rapid development. At the same time, all these contribute to expanding and deepening the research of Chinese ethical theory. For example, we can make the study of virtue in contemporary China closely follow the forefront of the west, and gradually build an ethical system with distinctive Chinese characteristics. The former can be seen as a direct academic dialogue between contemporary Chinese scholars and Western scholars, and even into the mainstream discourse system discussed in contemporary western countries. The latter can be shown as one of the most important theoretical resources and approaches, represented by the Confucian ethics as the most important theoretical resources and approaches, and in many respects the views, arguments and theories that are not deep or not deep in the discussion of contemporary western moral ethics are put forward in many respects. On the other hand, from the perspective of application value, it can introduce the "problems" and "methods" of contemporary western ethics, and explore and summarize the useful enlightenment and reference. This is the mutual criticism and interrogation between the two perspectives, which reflect the problems of the western society and the modern civilization, and even a great many serious threats to the existence of contemporary human beings, as well as the methods adopted in the clinics of these problems in a constructive manner, and a facet thinker has appeared to the modern civilization. And helpful exploration of some possible problems can promote Chinese scholars' awareness of these problems. Besides, from the solution of these problems, the thought of western thinkers is undoubtedly one of the important plans for China and mankind to solve the problem of modern civilization. It can provide important inspiration and reference for the discovery of problems and problems in the process of the prosperity of contemporary China and the world civilization. [9]For example, the importance of virtue can provide a new perspective to 
overcome the shortcomings of modern civilization and its negative consequences. Moral consciousness of Contemporary Western Virtue ethicists and a variety of virtue concept, the concept of happiness, the concept of care, which also has some connections with core values, rule of virtue and Chinese dream.

\section{ACKNOWLEDGEMENTS}

This paper is a periodical achievement of youth project of the National Social Science Fund: "The debate and significance research of contemporary western ethics of virtue and normative ethics” (item number: 17CZX054).

\section{REFERENCES}

[1] Fang Xi, Jiang Chang: "Debates and influences of virtue ethics and normative ethics", philosophy dynamics, 2017(3). (In Chinese)

[2] Crisp, Slote: Virtue ethics: a brief sketch, (translated by Wang Kai).Thought and culture ,2014 (1). (In Chinese)

[3] Fang Xi: "Thinking of integrating normative education with virtue education”. School party building and ideological education, 2016 (9). (In Chinese)

[4] Chen Zhen: "What is virtue ethics". Philosophical research, 2016(7). (In Chinese)

[5] Fang Xi: "Rule and virtue ethics: the development road of exploring", Journal of Hubei University, 2014 (5).

[6] Jiang Chang: “The history of virtue in the west”. People's press, 2016, P. 188. (In Chinese)

[7] Fang Xi: "A study of Bernard Williams's ethical thoughts-the bumpbroken from the modern normative ethics,Science Press, 2014, P.66. (In Chinese)

[8] (American) Alasdair McIntyre: "Who is the right? What kind of rationality", (transltated by Wu Haizhen, Wang Jinyi, Wan Junren), contemporary Chinese press, 1996,P.6. (In Chinese)

[9] Wan Junren: "Contrast and dialysis -- the modern vision of Chinese and Western Ethics”. Guangdong people's publishing house, 1998, P.98. (In Chinese) 